\title{
DisaPPEARANCE RATE OF BOVINE FETUSES at Grand Teton National Park, State ElK FEEDGROUNDS AND AT THE NATIONAL ELK REFUGE
}

\author{
WALTER E. COOK $\downarrow$ ELIZABETH S. WILLIAMS $\downarrow$ E. TOM THORNE
}

\section{ABSTRACT}

Brucellosis is a bacterial disease that causes elk and bison to abort and may have potential to be transmitted to domestic cattle. In this preliminary study we examined how long healthy bovine fetuses remained in the environment and could be available for contact by elk, bison, or cattle. Healthy bovine fetuses were placed on state elk feedgrounds, the National Elk Refuge, and Grand Teton National Park to simulate an elk or bison aborted fetus. Fetuses were monitored until they disappeared due to scavenging. Ninety percent of the fetuses disappeared from the National elk refuge within 31 hours, but it took 163 and 130 hours for fetuses to disappear from state feedgrounds and Grand Teton National Park, respectively. We found, via analysis of covariance, that there was a significant difference in fetal disappearance rates depending on where the simulated abortions occurred. We also found that aborted fetuses could potentially serve as a source of bacterial infection for several days. This preliminary study will be expanded to include greater numbers of animals and additional locations in coming seasons.

\section{$\uparrow \quad$ INTRODUCTION}

Bovine brucellosis is an important disease of domestic and wild animals and occasionally of humans. There is much debate, disagreement, and controversy about this disease and its impacts in the Greater Yellowstone Ecosystem. The debate has become highly political and has implications for the management of wildlife and livestock of the region.
A brucellosis outbreak occurred on a cattle ranch in Fremont County, Wyoming in 1988. The cattle herd had documented contact with both elk and bison. A USDA brucellosis epidemiologist could not identify a bovine source for the outbreak, and a federal judge ruled that the outbreak had a wildlife source (Parker Land \& Cattle Company, Inc. v. U.S., 796 F. Supp. 477, 488 [D. Wyo. 1992]). In this case, because the wildlife species responsible could not be determined, the responsible agency could not be determined. Still, the decision has implications for wildlife management agencies which could be held liable in the future for allowing the disease to be transmitted from wildlife to livestock.

In animals, the disease is transmitted by ingestion of Brucella abortus from contaminated fetuses, placentas, and associated fluids (Nicoletti, 1986). Bison (Bison bison) of Yellowstone National Park have been known to be infected with brucellosis since 1917 (Katz, 1941; McCorquodale and DiGiacomo, 1985). More recently, brucellosis was diagnosed in Grand Teton National Park bison near Jackson, Wyoming (Williams et al., 1993). Bison experimentally infected with $B$. abortus abort, but the frequency of abortion in free-ranging bison is not known (Davis et al., 1990; Williams et al., in press). Brucellosis is known to have caused abortion, retained placenta, and endometritis in a bison cow as well as epididymitis in a bull in Teton County, Wyoming. Additionally, $76 \%$ of the bison tested from this herd were serologically positive for brucellosis (Williams et al., 1993). Furthermore, brucellosis was documented to have spread from artificially infected bison to cattle when they were held in common paddocks (Davis et 
al., 1990). Still, the risks of transmission in a freeranging situation are unknown.

While brucellosis in bison receives more media attention, a greater number of elk (Cervus elaphus nelsoni) are actually infected with $B$. abortus. The disease affects elk herds that winter on feedgrounds in western Wyoming (Thorne et al., 1978a; Thorne et al., 1979). The elk of Yellowstone National Park and the National Elk Refuge in Jackson, Wyoming have been known to be infected since the 1930's (Rush, 1932; Thorne et al., 1978a). There are 23 feedgrounds in western Wyoming, which feed approximately 23,000 elk. Brucellosis has been documented in elk on 18 of these feedgrounds and is assumed to be present in elk on the remaining untested feedgrounds (Herriges et al., 1992; Thome et al., 1991). Seroprevalence is as high as $50 \%$ on some feedgrounds (Herriges et al., 1989). The abortion rate of naturally exposed naive elk is about $50 \%$, and highly infected herds may lose $12 \%$ of their reproductive potential (Thome et al., 1991).

Infected elk may be in close contact with cattle on summer ranges during migrations and occasionally on cattle winter feedlines (Thorne et al., 1979). Artificially infected elk can transmit brucellosis to susceptible cattle when they are confined together under conditions of prolonged close contact (Thorne et al., 1979), although the risk in a free-ranging situation is unknown.

The chances of brucellosis being transmitted from elk or bison to cattle under realistic field conditions are unknown. An important technique for evaluation of this question is through computer modeling. However, before reliable models for multispecies brucellosis problems can be created, specific important information is needed. One important gap in available data is the time over which an aborted fetus can serve as a source of $B$. abortus to other animals. A major factor limiting infectivity of the aborted fetus may be how quickly the fetus is scavenged and removed from the environment.

The main objective of this study was to ascertain if there were differences between fetal disappearance rates at various sites in northwestern Wyoming: state feedgrounds (SFs), the National Elk Refuge (NER), and Grand Teton National Park (GTNP).

\section{METHODS}

Healthy bovine fetuses weighing 4.1-22.7 kg were obtained from the Monfort slaughter house in Greeley, Colorado and from the Packerland slaughter house in Gering, Nebraska. Arrangements with the veterinary inspectors at the slaughter houses were made to obtain 30 healthy fetuses over the course of several weeks. Because fetal blood is quite valuable, these fetuses were purchased after blood had been removed. Each fetus came from cows serologically negative for Brucella antibodies. All fetuses were handled with rubber gloves to avoid getting human scent on them. Fetuses were placed into plastic bags, weighed, and frozen until used.

The first field study was conducted in middle to late March 1996 to correspond with the time that most abortions are believed to occur due to brucellosis in elk and bison. The study sites were on four of the state of Wyoming elk feedgrounds (Camp Creek, South Park, Horse Creek, and Grey's River) and the National Elk Refuge near Jackson, Wyoming.

Each fetus was thawed and removed from the plastic bag at the study site and placed on the feedline to mimic an actual aborted elk fetus. Fetuses were placed in separate locations at least a kilometer apart. Two fetuses were placed at each SF; one was introduced to the $\mathrm{SF}$ in the morning and one in the evening, with all fetuses being placed on the same day. Seven fetuses were placed at the NER over a two day period; three were placed in the morning, and four in the evening.

Fetuses were monitored at a distance with binoculars and spotting scopes for several hours after being placed on the site. Fetuses were then examined with binoculars or on an 8 to 12 hour basis. When the fetus could no longer be visualized with binoculars, we approached the area on foot until we were close enough to confirm presence or absence of the fetus. We also attempted to document the species of animal involved in scavenging the fetus by remote visualization and by the scats and footprints found at the site. Additionally, the area was carefully examined to make sure that the fetus was not dragged out of sight. We continued to monitor fetuses until they were completely scavenged. 
In May 1996, we carried out a similar study in Grand Teton National Park and surrounding area using 15 fetuses monitored in a similar manner to that prevously described. These study sites were on or near areas where there was potential contact between cattle and bison and/or elk on legislatively authorized cattle grazing allotments and driveways. Fetuses were placed at least two kilometers apart during the study. The general habitat type (grassland, sagebrush or forest) was recorded.

Disappearance times were defined as the time from placement of the fetus until the time when it was confirmed to be gone. The fetus may have disappeared several hours before its documented disappearance was confirmed. Time to disappearance of one fetus placed on the NER was discarded from the statistical analysis because we believe it to be an outlier. Data were analyzed by the mean disappearance rate for SFs, the NER and GTNP. Additionally, disappearance rates were described using a probability distribution assuming an exponential distribution. This distribution will be verified with a goodness of fit test when additional data are collected in subsequent studies. Also, an analysis of covariance (ANCOVA) using the SAS statistical package was used to determine if there were differences between sites. The ANCOVA considered habitat type and fetal weights as covariates.

\section{$\downarrow \quad$ RESULTS}

Results are summarized in the Tables 1-3. Many of the bovine fetuses were larger than elk fetuses at the appropriate stage in gestation. We were concerned that this may bias our results, but the ANCOVA showed that fetal weights did not significantly impact how quickly they disappeared $\left(\mathrm{p}=.93 ; \mathrm{H}_{0}\right.$ : weight has an impact).

\begin{tabular}{|c|c|c|c|c|c|c|c|}
\hline$=$ & سחמשת & (1) & 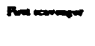 & $T^{T}=m$ & $\stackrel{n=m}{n=m}$ & $\min ^{a}$ & $\pi$ \\
\hline$m=\mathrm{cm}$ & $\sum_{n \rightarrow \infty}^{2+200}$ & 12.8 & החים & 0.0010 & ما & 3 & $1206(5.23+1)$ \\
\hline $\operatorname{mos} c$ & $x_{i t \leq 0}^{\infty x+\infty}$ & ఐ & $\infty$ & 135 & No & - & ctr.son \\
\hline . & $m_{n \rightarrow \infty}^{2 x+\infty}$ & s & in & ens & سلد سي سي & $>180$ & $\ln 20-(3 \times 4)$ \\
\hline 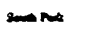 & 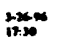 & 10.4 & 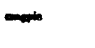 & meso & - & wo & 20.30 \\
\hline Dencot: & $\lim _{\infty \rightarrow \infty}$ & 0.6 & סוס & 000 & סונד & $>100$ & and \\
\hline$D_{n} \mathrm{~cm}$ & $\sum_{i \rightarrow \infty}^{2 x<\infty}$ & wos & wo & ND & No & so & neswo \\
\hline andions & ${ }_{10200}^{2,200}$ & 2.8 & $\infty$ & 1.170 & 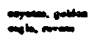 & 4 & $\pi \ln 00$ \\
\hline 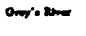 & $x_{i=\infty}^{3.2 x+\infty}$ & 11.7 & no & No & سוק & No & numan \\
\hline
\end{tabular}

Coyotes (Canis latrans) were the dominant scavenger at all locations. Bald eagles (Haliaeetus leucocephalus) and golden eagles (Aquila chrysaetos) and ravens (Corvus corax) consumed two entire fetuses on SFs and participated in scavenging at a third. Blackbilled magpies (Pica pica) were often the first species to scavenge, especially on the SFs. One fetus on GTNP appeared to be consumed by elk and bison after being initially fed upon by ravens.

We also documented elk and bison to orally contact fetuses on several occasions. On SFs, we documented elk making several contacts with fetuses. One fetus was contacted by over 100 elk and another by over 150 elk. This is probably an underestimate of the true number of contacts made because fetuses were not constantly monitored. We were unable to monitor most of the fetuses at the NER close enough to document contacts by elk. At GTNP, a few elk and bison were noted to have come close enough to fetuses to make contact, and as already mentioned, we believe that one fetus was scavenged primarily by elk and bison. Again, it is quite possible that more contacts occurred which we were unable to document.

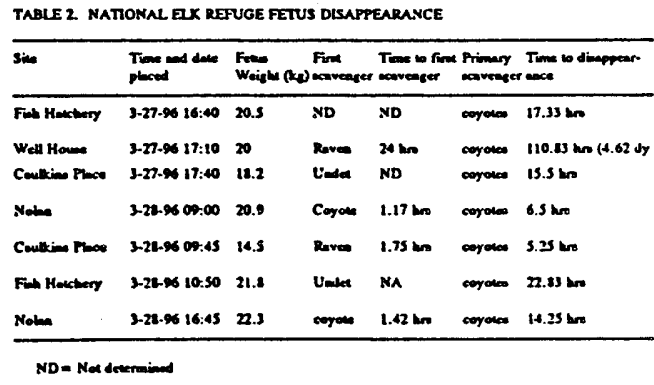

Mean time for a fetus to disappear was 70.9 hours at SFs 13.6 hours at the NER and 56.6 hours at GTNP. Assuming an exponential distribution, we estimated that $90 \%$ of the fetuses disappear from SFs within 163 hours (6.8 days), 31.3 hours (1.3 days) from the NER and within 130 hours (5.4 days) from GTNP.

The ANCOVA revealed significant differences in disappearance time of fetuses at the three sites $(p=.0057)$. However, there was only a significant difference between the SFs and the NER. Habitat type also made a significant difference in how quickly fetuses were scavenged $(p=.0057)$. Both the NER and the SFs consisted entirely of grassland, but GTNP contained three basic habitat types: grasslands, sagebrush communities and forests. We found that fetuses disappeared fastest on grasslands, followed by forests, and lasted longest in sagebrush. 


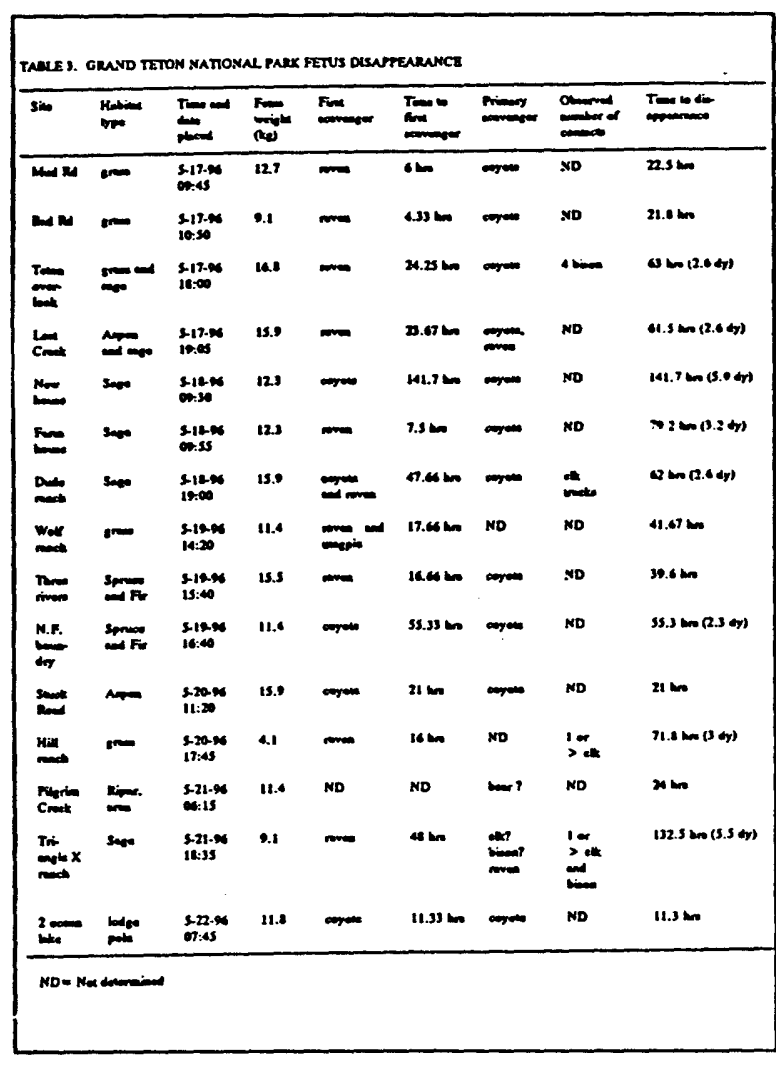

\section{$\downarrow \quad$ DISCUSSION}

We would like to emhasize that this represents a preliminary study with additional data to be gathered over the next two years. The conclusions we reach at the end of this project may be different from those drawn at this point in the study.

There were significant differences in fetal disappearance time among our study sites. Thus, it may be necessary that each site be considered independently when evaluating the dynamics of brucellosis transmission. Different management schemes may be needed at each of the sites. Additional data may help clarify if there are differences in fetal disappearance rates between the NER and GTNP and possibly between SFs and GTNP.

We feel justified in designating one fetus at the NER an outlier. It took almost five times longer for this fetus to disappear than the next longest lasting fetus at this site. In addition, this fetus was placed in an area with no landmarks, therefore, it was very difficult to monitor from a distance. To help us find it in the spotting scope we placed a red flag near it which was not needed with any other fetus. We feel that the flag scared off potential scavengers. Indeed, we witnessed an elk approach the fetus and shy away when a gust of wind blew the flag. Also, we saw a coyote directly downwind of the fetus sniffing the air coming from the fetus yet the coyote did not approach it. When we finally removed the flagging, the fetus was consumed in less than 24 hours.

At all three sites coyotes were the primary scavenger. Therefore, it was not surprising that fetuses at the NER disappeared faster. The NER is 10,000 ha with a post whelping coyote density of $1.5 / \mathrm{km}^{2}$ (Camenzind, 1978). Coyotes at this location are completely protected. The NER is large enough for most coyotes to spend their entire lives completely within its boundaries. The SFs, on the other hand, are much smaller. Coyotes are protected while on the SFs, but they may be shot and trapped on the surrounding lands. This may reduce the coyote population on the $\mathrm{SFs}$, but it may also make the coyotes more wary of human activity. Thus, coyotes may not consume fetuses as quickly on SFs which have some degree of human activity. At GTNP coyotes are also protected, but the coyote densities are probably lower than on the NER. Also, the variety of habitat types found at GTNP may prevent the fetuses from being removed as quickly as at the NER.

Removal time for fetuses was greater than expected. This information is important for understanding the risks of interspecific transmission. In GTNP, $10 \%$ of the bovine fetuses (as surrogates for elk or bison fetuses) could be expected to remain in the environment for longer than 130 hours (5.4 days). Thus, there is the potential for an aborted fetus to serve as a source of infection for several days. However, another important factor is bacterial survival time on a fetus, which is the subject of ongoing research.

It also appears that the type of habitat in which an abortion occurs may have a significant impact on how quickly the fetus is scavenged. We believe that fetuses disappear more quickly on grasslands because they are more visible, both from the ground and the air. In forests, visibility from the air is reduced, perhaps affecting avian scavenging. Visibility of fetuses in sagebrush habitat may be lowest, increasing time to scavenging. Avian scavengers were usually the first to arrive, thus visibility may be more important than scent in determining how quickly a fetus disappears. This is especially true if coyotes are attracted to areas of avian activity. Because fetuses disappear at different rates in different habitats it may be important to determine if 
abortions are more likely to occur in one habitat type over another.

A potential problem with this study was that bovine fetuses may not be realistic surrogates for elk and bison fetuses. It is possible that scavengers prefer elk and bison fetuses and might avoid bovine fetuses, at least initially. It is also possible that some human scent in the area would deter coyote scavenging. Our data from the NER suggest this was not a big problem. Still, we are hoping to obtain some healthy elk and/or bison fetuses to use in additional trials this spring to determine if bovine fetuses are inappropriate.

Our data suggest that abortions among elk and bison are relatively rare. Aborted fetuses on SFs are seldom found. The feeder at the Horse Creek SF has been feeding there for 16 years and in that time has found only two elk fetuses (H. Schwartzman pers. com.). Prior to this work we believed that the reason fetuses were found so rarely was that they were scavenged quickly. However, this research suggests that fetuses aren't scavenged immediately at least at SFs and GTNP. If elk commonly aborted, more fetuses likely would be found on feedgrounds each year. On the other hand, most feedgrounds have elk bedding areas which are only rarely visited by feeders. If elk tend to abort in these areas fetuses are unlikely to be found regardless of how long they remain prior to being scavenged. At GTNP, even though fetuses may be present for a relatively long period after being aborted, the chances of them being found and reported are still quite low because of the varied terrain and habitats and large area involved.

This study also documented elk and bison contacting bovine fetuses. Many of the elk on SFs were observed closely and seen to sniff and lick the fetus. This confirmed that elk and bison contact a fetus providing a mechanism for transmission of disease if the fetus is contagious. We also documented one fetus which was probably eaten by elk and/or bison. We found no evidence of any scavenger large enough to consume this fetus yet there were both elk and bison hoof prints and feces near the site of fetus placement. Additionally, we documented both elk and bison contacting this fetus several times prior to its disappearance. Elk are known to occasionally consume their own fetus after an abortion (E.T. Thorne pers. comm.), but have not been known to consume fetuses from another individual. We cannot tell from this study if elk or bison would contact conspecific fetuses at the rate observed here. It may be a strange odor or site of a bovine fetus which attracted the elk and bison, and they may tend to ignore conspecific abortions. However, elk have been observed to investigate conspecific abortions (E.T. Thorne, pers. comm.). Future studies with elk and/or bison fetuses may reveal how frequent contact with conspecific aborted fetuses are.

\section{$\downarrow \quad$ LITERATURE CITED}

Camenzind, F.J. 1978. Behavioral ecology of coyotes on the National Elk Refuge, Jackson, Wyoming. In Coyotes: biology, behavior, and management, M. Bekoff (ed.) Academic Press, New York, pp. 267-296.

Davis, D.S., J.W. Templeton, T.A. Ficht, J.D. Williams, J.D. Kopec, and L.G. Adams. 1990. Brucella abortus in captive bison. I. Serology, bacteriology, pathogenesis, and transmission to cattle. Journal of Wildlife Diseases. 26: 360-371.

Herriges, J.D., Jr., E.T. Thorne, S.L. Anderson, and H.A. Dawson. 1989. Vaccination of elk in Wyoming with reduced dose strain 19 Brucella: Controlled studies and ballistic implant field trials. Proceedings of the 93rd Annual Meeting of the United States Animal Health Association. 99: 24-27.

Herriges, J.D., E.T. Thome, and S.L. Anderson. 1992. Vaccination to control brucellosis on western Wyoming feed grounds. In The Biology of Deer, R.D. Brown (ed.). Springer-Verlag New York, Inc. pp. 107112.

Katz, J.S. 1941. Brucellosis in wildlife. Journal of American Veterinary Medical Association. 99: 24-27.

McCorquodale, S.M. and R.F. DiGiacomo. 1985. The role of wild North American ungulates in the epidemiology of bovine brucellosis: a review. Journal of Wildlife Diseases. 21: 351-357.

Nicoletti, P. 1986. Effects of brucellosis on bovine reproductive efficiency. In Current Therapy in Theriogenology, 2nd ed., D.A. Morrow (ed.). W.B. Saunders Company, pp. 271274. 
Parker Land \& Cattle Company, Inc. v. U.S., 796 F. Supp. 477, 488 [D. Wyo. 1992].

Rush, W.M. 1932. Bang's disease in the Yellowstone National Park buffalo and elk herds. Journal of Mammalogy 13: 371-372.

Thome, E.T., J.K. Morton, and G.M. Thomas. 1978a. Brucellosis in elk. I. Serological and bacteriological survey in Wyoming. Journal of Wildlife Diseases. 14: 74-81.

Thome, E.T., J.K. Morton, F.M. Blunt, and H.A. Dawson. 1978b. Brucellosis in elk. II. Clinical effects and means of transmission as determined through artificial infections. Joumal of Wildlife Diseases. 14: 280-291.

Thome, E.T., J.K. Morton, and W.C. Ray. 1979. Brucellosis, its effect and impact on elk in western Wyoming. In North American elk; ecology, behavior and management, M.S. Boyce and L.O. Hayden-Wing (eds.). University of Wyoming, Laramie, Wyoming, pp 212-220.
Thorne, E.T., M. Meager, and R. Hillman. 1991. Brucellosis in free-ranging bison: Three perspectives. In The greater Yellowstone ecosystem: Redefining America's wilderness heritage, R.B. Keiter and M.S. Boyce (eds.). Yale University Press, New Haven, Connecticut, pp. 275-287.

Williams, E.S., E.T. Thome, S.L. Anderson, and J.D. Herriges, Jr. 1993. Brucellosis in freeranging bison (Bison bison) from Teton County, Wyoming. Journal of Wildlife Diseases. 29: 118-122.

Williams, E.S., S.L. Cain, and D.S. Davis. Brucellosis: The disease in bison. National Symposium on Brucellosis in the Greater Yellowstone Area. Jackson Hole, Wyoming, September 26-28, 1994. (In press). 